\title{
Patient and tumor factors contributing to distant metastasis in well-differentiated thyroid cancer: a retrospective cohort study
}

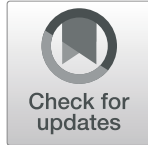

Usman Khan ${ }^{1 *}$ D, Ayham Al Afif ${ }^{2}$, Abdullah Aldaihani ${ }^{2}$, Colin MacKay², Matthew H. Rigby ${ }^{2}$, Murali Rajaraman ${ }^{3}$, Syed Ali Imran ${ }^{4}$, Martin J. Bullock, S. Mark Taylor ${ }^{2}$, Jonathan R. B. Trites ${ }^{2}$ and Robert D. Hart ${ }^{6}$

\begin{abstract}
Background: Distant metastasis in thyroid cancer significantly reduces survival in patients with well-differentiated thyroid carcinoma (WDTC). There is limited information available to clinicians regarding pathological features that confer a higher risk of distant metastasis (DM). This study aimed to identify patient and tumor factors that were associated with the development of DM over time in patients with WDTC.
\end{abstract}

Methods: A retrospective cohort analysis of patients with WDTC $(n=584)$ at our institution was performed between 2007 and 2017. A total of 39 patients with DM and 529 patients with no DM (NDM) were included. Patient demographics, tumor characteristics and patient survival were compared between the DM and NDM groups using a univariate analysis. Multivariate Cox-proportional hazards model was used to evaluate the risk of developing distant metastasis over time. Kaplan-Meier analysis was used to compare survival between the DM and NDM groups.

Results: Distant metastasis had a substantial impact on disease-specific survival (DSS) at 5 and 10-years in the DM group; $71.0 \%$ (SE 8.4\%) and $46.9 \%$ (SE 11.6\%) respectively, compared to 100\% survival in the NDM group ( $p<0.001$ ). The DM group had significantly higher proportions of males, lymphovascular invasion (LVI), nodal metastasis (NM), large tumor size (TS), extrathyroidal extension (ETE), positive resection margins, multifocality, follicular thyroid cancer (FTC), tall cell variant of papillary thyroid cancer (PTC), and Hurthle cell carcinoma (HCC), when compared to the NDM group ( $p<0.05$ ). A TS $\geq 2 \mathrm{~cm}$ (Hazard Ratio (HR) 1.370), NM (HR 3.806) and FTC (HR 7.068) were associated with a significantly increased hazard of developing distant metastasis in patients with WDTC.

Conclusions: TS $\geq 2 \mathrm{~cm}, \mathrm{NM}$ and FTC are associated with a significantly increased propensity for developing DM in our cohort of WDTC patients.

Keywords: Distant metastasis, Thyroid cancer, Well differentiated thyroid cancer, Metastatic thyroid cancer, Thyroid cancer survival

\footnotetext{
* Correspondence: usman.khan@dal.ca

This paper was presented at the Canadian Society of Otolaryngology-Head and Neck Surgery Conference (CSOHNS) in Edmonton, Alberta, Canada on June $3^{\text {rd }}, 2019$.

${ }^{1}$ Faculty of Medicine, Dalhousie University, 1459 Oxford Street, Halifax, Nova

Scotia B3H 4R2, Canada

Full list of author information is available at the end of the article
}

\section{BMC}

(c) The Author(s). 2020 Open Access This article is licensed under a Creative Commons Attribution 4.0 International License, which permits use, sharing, adaptation, distribution and reproduction in any medium or format, as long as you give appropriate credit to the original author(s) and the source, provide a link to the Creative Commons licence, and indicate if changes were made. The images or other third party material in this article are included in the article's Creative Commons licence, unless indicated otherwise in a credit line to the material. If material is not included in the article's Creative Commons licence and your intended use is not permitted by statutory regulation or exceeds the permitted use, you will need to obtain permission directly from the copyright holder. To view a copy of this licence, visit http://creativecommons.org/licenses/by/4.0/ The Creative Commons Public Domain Dedication waiver (http://creativecommons.org/publicdomain/zero/1.0/) applies to the data made available in this article, unless otherwise stated in a credit line to the data. 


\section{Background}

The incidence of well-differentiated thyroid cancer (WDTC) has increased substantially in recent years, largely owing to a more widespread use of sensitive diagnostic techniques [1]. Improved multidisciplinary treatment regimens have enhanced patient survival rates, estimated at 95\% and higher over 10 years [2]. Although distant metastasis (DM) in WDTC remains uncommon, it is associated with a significantly lower disease-specific survival (DSS), estimated at 30-50\% (5-10 years), compared to patients with no DM [3-5].

While several studies have reported the prognosticators of survival [5-10], local recurrence and mortality [6, $11,12]$ in WDTC, there remains a lack of information regarding the pathological predictors of DM in this population. Specifically, there is limited information regarding the contributions of aggressive pathological subtypes of WDTC $[5,6]$ in the development of DM, such as non-classical subtypes of papillary thyroid carcinoma (PTC) (tall cell, oncocytic variants), follicular thyroid carcinoma (FTC) and Hurthle cell carcinoma (HCC). The impact of pathological features such as tumor size, lymphovascular invasion, nodal metastasis, multifocality and positive resection margins also remain controversial [13-16]. While some studies have investigated DM in WDTC, there are limited studies utilizing a statistical model that evaluates the development of DM over time for clinically-relevant pathological features.

In this study, we investigated our cohort of WDTC patients to identify patient and pathological factors that are associated with the development of DM over time. Given that PTC is the most common thyroid malignancy with the most favorable clinical outcomes, a separate subgroup analysis of patients with PTC was also conducted. We also report on one of the largest samples of patients with WDTC and DM in the Canadian literature. The overall aim of this study was to better understand the pathological predictors for developing DM in thyroid carcinoma, which will ultimately better identify, and inform the management of, patients with WDTC.

\section{Methods}

The interdisciplinary thyroid cancer database (ITCD) is a computerized registry at our institution which prospectively collects information on all patients referred to the thyroid oncology clinic. A thorough search of the ITCD at our institute from 2007 to 2017 identified 584 patients with a diagnosis of thyroid carcinoma, confirmed on post-operative pathology. Patients with medullary thyroid carcinoma and anaplastic thyroid carcinoma were excluded $(n=16)$. A total of 39 patients with a diagnosis of thyroid carcinoma and distant metastasis (DM) were identified. Patients were included whether DM was diagnosed on initial presentation or throughout the course of treatment. The remaining 529 patients were included as the non-distant metastasis group (NDM). A diagnosis of DM was confirmed with a combination of biopsy of the site of metastasis, positron emission tomography (PET) scan and/or computed tomography (CT), and Iodine-131 scan.

Variables analyzed included age at diagnosis, sex, pathological type of thyroid cancer, histological subtype, primary tumor size $(\mathrm{cm})$, focality, lymphovascular invasion (LVI), margin status, extrathyroidal extension (ETE) and nodal metastasis (NM). Multifocal disease was defined by the presence of $\geq 3$ tumor foci. This was based on findings by $\mathrm{Al}$ Afif et al. where $\geq 3$ foci led to a significantly increased propensity for NM [17]. We also compiled data on therapeutic strategies of patients including surgical resection of distant metastasis, the number of radioactive iodine (RAI) treatments, and whether or not external beam radiation therapy (EBRT) was delivered. Cumulative and disease-specific survival were computed for both patient groups, followed by an analysis of variables contributing to the risk of developing DM. A tumor size of $2 \mathrm{~cm}$ was associated with increased mortality in previous articles and was therefore used as a cutoff for our hazard model analysis of DM $[16,18,19]$.

\section{Statistical analysis}

Univariate analysis was performed using Fisher's exact test or Chi Square test for categorical variables, and Mann-Whitney U test for continuous variables. Cumulative and disease-specific survival plots were generated using the Kaplan-Meier method. Differences in survival were tested using log-rank comparisons. The multivariate Cox proportional hazard model was utilized to evaluate the association of variables with the development of DM over time. All statistical analysis was conducted on SPSS (IBM SPSS Statistics 25). A p-value of $<0.05$ was considered significant for all tests.

\section{Results}

Demographics and tumor pathology

Clinical and pathological variables were analyzed in both the NDM $(n=529)$ and DM $(n=39)$ patient groups (Table 1). Patients with DM, when compared with those in the NDM group, were older at diagnosis ( 55 years \pm 16.6 vs. 50 years $\pm 14.4 p=0.026$ ); were more likely to be male ( $46 \%$ vs. $24 \%, p=0.002)$; had larger mean tumor size $(4.5 \mathrm{~cm} \pm 3$ vs $2.0 \mathrm{~cm} \pm 1.7, p<0.001)$; had multifocal tumors (69.2 vs. $30.1 ; p<0.001)$; had LVI ( $81 \%$ vs $29 \%$; $p<0.001)$; had NM (62.9\% vs. $26.1 \% ; p<0.001)$; had ETE (48.4\% vs $23.4 \% ; p=0.002)$ and positive tumor resection margins (46.9\% vs. $26.5 \% ; p=0.013)$.

The distribution of tumor histopathology is summarized in Table 2. PTC was the most prevalent entity in both groups with the classical subtype being commonest 
Table 1 Clinical and pathological characteristics of DM $(n=39)$ and NDM $(n=529)$ groups

\begin{tabular}{llll}
\hline Variable & DM & NDM & p-value \\
\hline Sex (\% M:F) & $46: 54$ & $24: 76$ & 0.002 \\
Average age (SD) (years) & $55(16.6)$ & $50(14.4)$ & 0.026 \\
Average tumor size (SD) (cm) & $4.5(3.0)$ & $2.0(1.7)$ & $<0.001$ \\
Multifocal (\%) & 69.2 & 30.1 & $<0.001$ \\
Positive margins (\%) & 46.9 & 26.5 & 0.013 \\
LVI (\%) & 81.2 & 29.4 & $<0.001$ \\
Nodal metastasis (\%) & 62.9 & 26.1 & $<0.001$ \\
ETE (\%) & 48.4 & 23.4 & 0.002 \\
\hline
\end{tabular}

DM Distant metastasis, NDM Non-distant metastasis, LVI Lymphovascular invasion, ETE Extrathyroidal extension

(46.4\% in DM and 45.3\% in NDM respectively; $p<0.05$ ). There were fewer cases of the follicular subtype of PTC in the DM compared with the NDM group $(14.3 \%$ vs $30.5 \%$, respectively; $p=0.05$ ). However, DM group compared with NDM group had a higher preponderance of tall cell variant of PTC (14.3\% vs $2.5 \% ; p=0.028)$, FTC $(12.8 \%$ vs $2.1 \% ; p=0.003)$ and HCC $(15.4 \%$ vs $1.1 \%$ in NDM; $p<0.001)$ respectively. There was no significant difference $(p>0.05)$ in the distribution of the oncocytic subtype of PTC (7.1 and 1.8\%, respectively) and micropapillary carcinoma ( 3.6 and $5.5 \%$ respectively) between the DM and NDM groups.

\section{Clinical presentation and therapeutic strategies}

Of the 39 patients with DM, 12 had evidence of DM at the time of initial presentation whereas 27 developed DM during the course of their disease (Table 3). The commonest clinical manifestations in patients with DM on initial presentation were pathological fractures in $7 /$ 12 (58\%) patients and pulmonary symptoms or incidental findings of pulmonary nodules on imaging in 5/12 (42\%) patients. The first site of DM was seen in the lungs in 24/39 (62\%) patients; bone in 12/39 (31\%); brain

Table 2 Distribution of tumor histopathology in DM and NDM patient groups

\begin{tabular}{lll}
\hline Tumor Type & DM \% & NDM (\%) \\
\hline Papillary Thyroid Carcinoma* & 71.8 & 96.7 \\
Classical subtype & 46.4 & 45.3 \\
Tall Cell subtype & 14.3 & 2.5 \\
Follicular subtype & 14.3 & 30.5 \\
Oncocytic subtype & 7.1 & 1.8 \\
Microcarcinoma & 3.6 & 5.5 \\
Other or unknown & 14.3 & 14.4 \\
Hurthle Cell Carcinoma* & 15.4 & 1.1 \\
Follicular Cell Carcinoma* & 12.8 & 2.1 \\
\hline
\end{tabular}

$D M$ Distant metastasis, NDM Non-distant metastasis ${ }^{*} p<0.05$ in $1 / 39$ (3\%); mediastinal lymph nodes in $1 / 39$ (3\%). One patient (3\%) had metastasis to multiple sites simultaneously. The anatomical sites of DM based on whether it occurred on presentation or throughout the course of the disease are further delineated in Table 3. The management of patients with DM is highlighted in Table 3. All patients with DM received at least one cycle of RAI, with $17 / 39$ (44\%) receiving more than 1 cycle. EBRT was administered in $22 / 39$ cases (56\%). In patients with DM, 13/39 (33\%) were offered distal metastatectomy.

Univariate analysis was used to compare patients with DM on presentation with those who developed DM during the course of their treatment (Table 4). Positive margins $(p=0.019)$ and $\operatorname{ETE}(p=0.032)$ were significantly more prevalent in the group that developed DM after diagnosis. Sex, age, tumor size, LVI, NM, tumor histology and focality were not significantly different between both groups.

\section{Multivariate analysis}

Multivariate Cox proportional hazards model was used to determine which covariates were independently associated with the development of DM over time (Table 5). Of the ten covariates tested, only tumor size $\geq 2 \mathrm{~cm}$ (Hazard Ratio $(\mathrm{HR})=1.37$, 95\% confidence interval $(\mathrm{CI})=1.135-1.655, \quad p=0.001), \quad \mathrm{NM} \quad(\mathrm{HR}=3.806, \quad 95 \%$ $\mathrm{CI}=1.285-11.270, p=0.016)$ and FTC $(\mathrm{HR}=7.068,95 \%$ $\mathrm{CI}=1.869-26.731, p=0.004)$ had a statistically significant increased HR for DM.

\section{Subgroup analysis of papillary thyroid Cancer patients}

Multivariate Cox proportional hazards model was performed to determine which covariates were independently associated with the development of distant metastasis over time in patients with PTC only (Table 6). Tumor size $\geq 2$ $\mathrm{cm}(\mathrm{HR}=1.354,95 \% \mathrm{CI}=1.113-1.649, p=0.002)$, increasing age $(\mathrm{HR}=1.035,95 \% \mathrm{CI}=1.000-1.071, p=0.048)$, multifocality $(\mathrm{HR}=3.032,95 \% \mathrm{CI}=1.120-8.206, p=0.029)$ and $\mathrm{NM}(\mathrm{HR}=4.761,95 \% \mathrm{CI}=1.457-15.553, p=0.01)$ had a statistically significant increased HR for DM.

\section{Survival}

DSS and overall survival (OS) at 10 years are shown in Figs. 1 and 2 respectively. DSS at 5- and 10-years for the DM group were 71\% (standard error (SE) 8.4\%) and 46.9\% (SE 11.6\%). DSS for the NDM group at 5- and 10 years were 100 and $100 \%$ respectively. OS at 5- and 10years for the DM group were 68.1\% (SE 8.6\%) and 44.9\% (11.3\%). OS for the NDM group at 5- and 10 years were 97.2\% (SE 1\%) and 87.9\% (SE 4.4\%) respectively.

\section{Discussion}

Overall, the body of evidence available to clinicians for assessing a patient's risk for developing DM is limited. A 
Table 3 Clinical features and therapeutic management of patients in the DM group $(n=39)$ based on initial presentation with DM $(n=12)$ or development of DM after initial diagnosis $(n=27)$

\begin{tabular}{|c|c|c|c|}
\hline Variable & Presented with DM $n$ (\%) & Developed DM after diagnosis $n(\%)$ & Total $n(\%)$ \\
\hline \multicolumn{4}{|l|}{ Presenting Symptom } \\
\hline Pathological fracture & $7(58)$ & - & - \\
\hline Pulmonary symptoms or incidental lung nodules & $5(42)$ & - & - \\
\hline \multicolumn{4}{|l|}{ Presenting site of DM } \\
\hline Lung & $5(42)$ & $19(70)$ & $24(62)$ \\
\hline Bone & $7(58)$ & $5(19)$ & $12(31)$ \\
\hline Brain & $0(0)$ & $1(3)$ & $1(3)$ \\
\hline Mediastinum & $0(0)$ & $1(3)$ & $1(3)$ \\
\hline Multiple sites & $1(3)$ & $0(0)$ & $1(3)$ \\
\hline Multiple sites of DM & $8(67)$ & $10(37)$ & $18(46)$ \\
\hline \multicolumn{4}{|l|}{ Treatment } \\
\hline 1 RAl cycle & $12(100)$ & $27(100)$ & $39(100)$ \\
\hline$>1$ RAl cycle & $6(50)$ & $11(41)$ & $17(44)$ \\
\hline EBRT & $10(83)$ & $12(44)$ & $22(56)$ \\
\hline Metastectomy & $7(58)$ & $6(22)$ & $13(33)$ \\
\hline
\end{tabular}

DM Distant metastasis, RAI Radioactive iodine, EBRT External beam radiation therapy

recent meta-analysis of articles using univariate comparisons has identified male sex, advanced age, tumor size, multifocality, LVI, ETE and lymph node metastasis as risk factors for DM in WDTC [20]. Our study demonstrates similar outcomes [20]. Our data shows a significantly higher proportion of male patients, larger tumors, LVI, positive resection margins, multifocality ( $\geq 3$ foci), ETE and nodal metastasis in the DM group when compared with the NDM group [5, 20]. Additionally, PTC was less prevalent in DM patients, with significantly larger proportions of FTC, when compared with the NDM group. We also investigated the impact of PTC subtype and $\mathrm{HCC}$ on the development of DM. We found

Table 4 Univariate analysis of patients in the DM group comparing those with DM on initial presentation $(n=12)$ and those who presented after their diagnosis of thyroid cancer $(n=27)$

\begin{tabular}{ll}
\hline Variable & $\boldsymbol{p}$-value \\
\hline Sex & 0.999 \\
Focality & 0.061 \\
Positive margins* & 0.019 \\
LVI & 0.148 \\
Nodal metastasis & 0.258 \\
Age at diagnosis & 0.563 \\
Size & 0.253 \\
ETE* & 0.032 \\
\hline
\end{tabular}

LVI Lymphovascular invasion ${ }^{*} p<0.05$ significantly higher proportions of tall cell variant of PTC and HCC in DM patients when compared to the NDM group. A pathological diagnosis of FTC was also a significant predictor of distant metastasis in our Cox proportional hazard model analysis. Moreover, many patients with tall cell variant of PTC or HCC experienced an aggressive progression of their disease with multiple sites of DM. Our findings suggest that the disproportionally higher rates of tall cell variant of PTC, HCC and FTC in DM patients are clinically important risk factors for the development of DM.

Table 5 Hazard ratios by Cox proportional hazards model for predicting the risk of distant metastasis in WDTC in DM and NDM patients $(n=568)$

\begin{tabular}{lllll}
\hline Variable & HR & Lower CI & Upper Cl & $\boldsymbol{p}$-value \\
\hline Age & 1.023 & 0.993 & 1.055 & 0.131 \\
Sex & 1.503 & 0.607 & 3.722 & 0.378 \\
Follicular & 7.068 & 1.869 & 26.731 & $0.004^{\dagger}$ \\
Hurthle & 1.945 & 0.416 & 9.086 & 0.398 \\
Size & 1.370 & 1.135 & 1.655 & $0.001^{\dagger}$ \\
Focality & 1.850 & 0.764 & 4.482 & 0.173 \\
Positive Margins & 0.974 & 0.374 & 2.540 & 0.957 \\
LVI & 2.488 & 0.719 & 8.613 & 0.15 \\
Nodal Metastasis & 3.806 & 1.285 & 11.270 & $0.016^{*}$ \\
ETE & 0.883 & 0.311 & 2.502 & 0.815 \\
\hline
\end{tabular}

LVI Lymphovascular invasion, ETE Extrathyroidal extension, CI Confidence interval ${ }^{*} p<0.05$ 
Table 6 Hazard ratios by Cox proportional hazards model for all DM and NDM patients with PTC $(n=540)$ to predict the risk of distant metastasis

\begin{tabular}{lllll}
\hline Variable & HR & Lower Cl & Upper Cl & $\boldsymbol{p}$-value \\
\hline Age & 1.035 & 1.000 & 1.071 & $0.048^{*}$ \\
Sex & 1.382 & 0.518 & 3.684 & 0.518 \\
Size & 1.354 & 1.113 & 1.649 & $0.002^{*}$ \\
Focality & 3.032 & 1.120 & 8.206 & $0.029^{*}$ \\
Positive Margins & 1.068 & 0.373 & 3.056 & 0.903 \\
LVI & 1.748 & 0.465 & 6.575 & 0.409 \\
Nodal Metastasis & 4.761 & 1.457 & 15.553 & $0.01^{*}$ \\
ETE & 0.942 & 0.278 & 3.189 & 0.923 \\
\hline
\end{tabular}

LVI Lymphovascular invasion, ETE Extrathyroidal extension ${ }^{*} p<0.05$

Previous reports have mostly focused on survival prognosticators in patients who have already developed DM or performed univariate comparisons between NDM and DM patients [20]. A statistical model assessing the risk or hazard over time for developing DM for selected pathological variables in a cohort of WDTC patients is less common in the literature. In our study, the pathological variables identified in the univariate analysis were used to better assess their impact on the development of DM. Using this model, a tumor size $\geq 2 \mathrm{~cm}(\mathrm{HR}=1.4)$, nodal metastasis $(\mathrm{HR}=3.8)$ and follicular carcinoma $(H R=7)$ were the only significant variables associated with an increased chance for developing DM over time. Interestingly, a tumor size $\geq 2 \mathrm{~cm}$ has also been correlated with increased mortality and adverse outcomes in patients with WDTC [16]. The age of patients, positive resection margins, ETE and sex were not associated with a risk of developing DM. Although age has been associated with improved survival in DM patients [10], our analysis did not demonstrate age as a significant factor for developing DM. This can partly be a result of wide age ranges in our dataset. However, as our model investigates the development of DM overtime, younger age may only be a prognosticator of survival once a

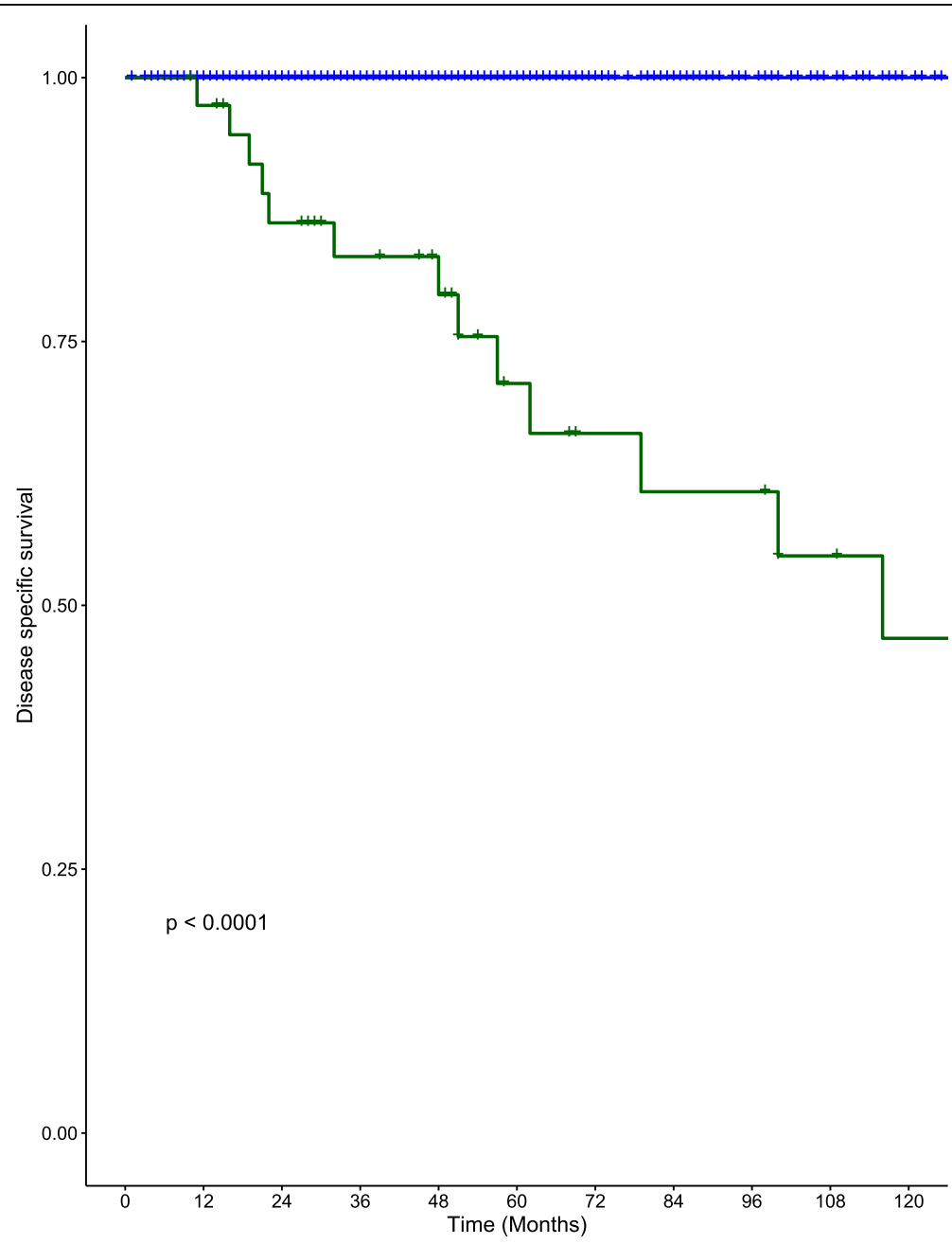

Fig. 1 Kaplan-Meier curves for DSS in the DM (red) and NDM groups (blue) for patients with well-differentiated thyroid cancer 


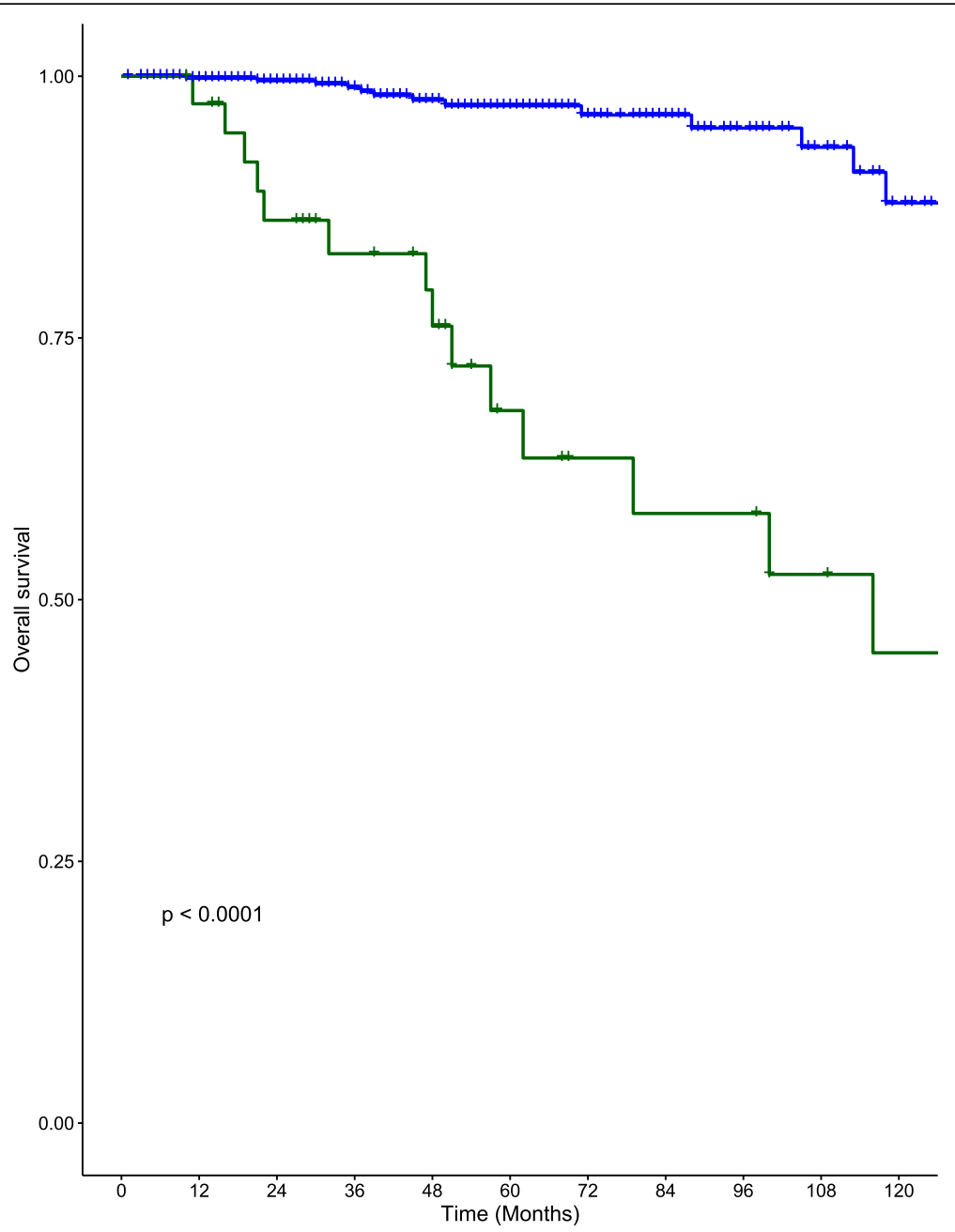

Fig. 2 Kaplan-Meier curves for OS in the DM (red) and NDM groups (blue) for patients with well-differentiated thyroid cancer

diagnosis of DM is reached as other studies have suggested [10]. Age was a significant factor in the subgroup analysis of PTC patients alone. The literature remains divided on the predictive value of multifocality in regard to tumor recurrence, metastasis and mortality $[12,21]$. The presence of $\geq 3$ foci were not a predictor of DM in our full patient cohort despite showing a propensity for nodal metastasis in previous research [17]. However, the presence of $\geq 3$ foci was significant for an increased likelihood of developing DM in our subgroup analysis of PTC patients alone alongside a tumor size $\geq 2 \mathrm{~cm}$, nodal metastasis and increased age.

The presence of DM had a substantial impact on survival in our cohort of WDTC patients (5-year and 10year DSS of 71.0 and $46.9 \%$ respectively). Despite a multimodal approach to treatment, including RAI, EBRT and surgical resection of distant tumors, the overall survival remained significantly diminished in DM patients (OS $44.9 \%$ at 10 years, $p<0.001$ ). These results emphasize the importance of early detection of patients that exhibit a greater risk of developing DM from WDTC.

The present study has several limitations. It is a retrospective chart review from a single institution. The sample size of the DM group is another limitation of our study. This is partly due to the rarity of DM in WDTC. Multi-center cohort studies are needed to mitigate sample size as a limitation considering the rarity of DM in thyroid carcinoma. Sample sizes required to generate more statistical power should roughly be greater than $68 \mathrm{DM}$ patients according to our sample size estimates for a singlevariable cox-proportional hazard model [22]. Given the small sample size, it is also difficult to separately analyze patients who developed DM throughout their treatment, compared to those who presented with DM. However, sparing positive resection margins and ETE, there were no significant differences between the groups. Future studies will focus on differentiating between the two groups. Future research is also 
investigating the influence of tumor driver mutations on the development of distant metastasis.

\section{Conclusion}

WDTC patients with a tumor size $\geq 2 \mathrm{~cm}$, NM and FTC on final pathology demonstrated a significantly increased propensity for developing DM. A subgroup analysis of PTC patients alone revealed increased age, presence of $\geq 3$ foci, NM and tumor size $\geq 2 \mathrm{~cm}$ as significant contributors for the development of DM. Patients with DM have disproportionally higher frequencies of tall cell subtype of PTC, HCC and FTC. Our findings add to the existing literature on pathological risk factors for developing DM in WDTC, which will ultimately better inform the management of this patient group.

\section{Abbreviations}

DM: Distant metastasis; NDM: Non-distant metastasis; WDTC: Welldifferentiated thyroid cancer; PTC: Papillary thyroid cancer; FTC: Follicular thyroid cancer; HCC: Hurthle cell carcinoma; LVI: Lymphovascular invasion; NM: Nodal metastasis; TS: Tumor size; ETE: Extrathyroidal extension; PET: Positron emission tomography; CT: Computed tomography; OS: Overall survival; DSS: Disease-specific survival; HR: Hazard ratio

\section{Authors' contributions \\ UK participated in data collection, data analysis, statistical analysis and writing of manuscript. AA was involved with data analysis and writing of manuscript. AA was involved in data collection and writing of manuscript. CM and MR performed statistical analysis. MR, JT and MT assisted with the overall design of the study methodology and manuscript editing. MR and $\mathrm{Al}$ populated the interdisciplinary thyroid cancer database. MB provided pathological reports. $\mathrm{RH}$ participated in study conceptualization, study design, manuscript writing and editing. All authors have approved and read the final manuscript.}

\section{Funding}

There was no funding obtained for this research study.

\section{Availability of data and materials}

Datasets are unavailable for this study as it would compromise patient privacy. However, further information regarding the data are available, within limits of patient privacy, upon request.

\section{Ethics approval and consent to participate}

Quality assurance project as per Capital Health Research Ethics Board guidelines.

\section{Competing interests}

The authors declare that they have no competing interests.

\footnotetext{
Author details

${ }^{1}$ Faculty of Medicine, Dalhousie University, 1459 Oxford Street, Halifax, Nova Scotia B3H 4R2, Canada. ${ }^{2}$ Division of Otolaryngology - Head and Neck Surgery, Dalhousie University, Dickson Building, QEll Health Sciences Centre, 5820 University Avenue, Halifax, Nova Scotia B3H 2Y9, Canada. ${ }^{3}$ Department of Radiation Oncology, Dalhousie University, Nova Scotia Cancer Centre, 5820 University Avenue, Halifax, NS B3H 1V7, Canada. ${ }^{4}$ Division of Endocrinology \& Metabolism, Department of Medicine, Dalhousie University, 1276 South Park Street, Suite 7-North-048 Victoria Building, Halifax, NS B3H 2Y9, Canada. ${ }^{5}$ Department of Pathology, Dalhousie University, DJ Mackenzie Building, 5788 University Avenue, Halifax, Nova Scotia B3H 2Y9, Canada. ${ }^{6}$ Division of Otolaryngology - Head and Neck Surgery, University of Calgary, ENT Clinic, 1820 Richmond Road SW, Calgary, AB T2T 5C7, Canada.
}

Received: 25 July 2019 Accepted: 21 September 2020

Published online: 16 November 2020

\section{References}

1. Davies L, Welch HG. Current thyroid cancer trends in the United States. JAMA Otolaryngol Head Neck Surg. 2014;140:4.

2. Ganly I, Nixon IJ, Wang LY, Palmer FL, Migliacci JC, Aniss A, Sywak M, Eskander AE, Freeman JL, Campbell MJ, Shen WT, Vaisman F, Momesso D, Corbo R, Vaisman M, Shaha A, Tuttle RM, Shah JP, Patel SG. Survival from differentiated thyroid Cancer: what has age got to do with it? Thyroid. 2015; 25:10.

3. Sugitani I, Fujimoto Y, Yamamoto N. Papillary thyroid carcinoma with distant metastases: survival predictors and the importance of local control. Surgery. 2008;143:1.

4. Wang LY, Palmer FL, Nixon IJ, Thomas D, Patel SG, Shaha AR, Shah JP, Tuttle RM, Ganly I. Multi-organ distant metastases confer worse disease-specific survival in differentiated thyroid cancer. Thyroid. 2014;24:11.

5. Clark JR, Lai P, Hall F, Borglund A, Eski S, Freeman JL. Variables predicting distant metastases in thyroid cancer. Laryngoscope. 2005;115:4.

6. Chrisoulidou A, Boudina M, Tzemailas A, Doumala E, lliadou PK, Patakiouta F, Pazaitou-Panayiotou K. Histological subtype is the most important determinant of survival in metastatic papillary thyroid cancer. Thyroid Res. 2011:4:1.

7. Schlumberger M, Tubiana M, De Vathaire F, Hill C, Gardet $P$, Travagli JP, Fragu P, Lumbroso J, Caillou B, Parmentier C. Long-term results of treatment of 283 patients with lung and bone metastases from differentiated thyroid carcinoma. J Clin Endocrinol Metab. 1986;63:4

8. Nixon IJ, Whitcher MM, Palmer FL, Tuttle RM, Shaha AR, Shah JP, Patel SG, Ganly I. The impact of distant metastases at presentation on prognosis in patients with differentiated carcinoma of the thyroid gland. Thyroid. 2012;22:9.

9. Sampson E, Brierley JD, Le LW, Rotstein L, Tsang RW. Clinical management and outcome of papillary and follicular (differentiated) thyroid cancer presenting with distant metastasis at diagnosis. Cancer. 2007;110:7.

10. Hirsch D, Levy S, Tsvetov G, Gorshtein A, Slutzky-Shraga I, Akirov A, Robenshtok E, Shimon I, Benbassat CA. Long term outcomes and prognostic factors in patients with differentiated thyroid Cancer and distant metastasis. Endocrine Pract. 2017:23(10):1193-200.

11. Barbosa MP, Momesso D, Bulzico DA, Farias T, Dias F, Lima RA, Corbo R, Vaisman M, Vaisman F. Metastatic lymph node characteristics as predictors of recurrence/persistence in the neck and distant metastases in differentiated thyroid cancer. Arch Endocrinol Metab. 2017:61:6.

12. Joseph KR, Edirimanne S, Eslick GD. Multifocality as a prognostic factor in thyroid cancer: a meta-analysis. Int J Surg. 2018;50:121.

13. Cheng SP, Chien MN, Wang TY, Lee JJ, Lee CC, Liu CL. Reconsideration of tumor size threshold for total thyroidectomy in differentiated thyroid cancer. Surgery. 2018;164:504.

14. Tam S, Amit M, Boonsripitayanon M, Busaidy NL, Cabanillas ME, Waguespack SG, Gross ND, Grubbs EG, Williams MD, Lai SY, Sturgis EM, Zafereo ME. Effect of tumor size and minimal Extrathyroidal extension in patients with differentiated thyroid cancer. Thyroid. 2018;28:8.

15. Haugen BR, Alexander EK, Bible KC, Doherty GM, Mandel SJ, Nikiforov YE, Pacini F, Randolph GW, Sawka AM, Schlumberger M, Schuff KG, Sherman SI, Sosa JA, Steward DL, Tuttle RM, Wartofsky L. 2015 American Thyroid Association management guidelines for adult patients with thyroid nodules and differentiated thyroid Cancer: the American Thyroid Association guidelines task force on thyroid nodules and differentiated thyroid Cancer. Thyroid. 2016;26:1

16. Nguyen XV, Roy Choudhury K, Tessler FN, Hoang JK. Effect of tumor size on risk of metastatic disease and survival for thyroid Cancer: implications for biopsy guidelines. Thyroid. 2018;28:3.

17. Al Afif A, Williams BA, Rigby MH, Bullock MJ, Taylor SM, Trites J, Hart RD. Multifocal papillary thyroid Cancer increases the risk of central lymph node metastasis. Thyroid. 2015;25:9.

18. Han K, Kim EK, Kwak JY. 1.5-2 cm tumor size was not associated with distant metastasis and mortality in small thyroid cancer: A population-based study. Sci Rep. 2017;7:46298.

19. Machens $\mathrm{A}$, Holzhausen $\mathrm{HJ}$, Dralle $\mathrm{H}$. The prognostic value of primary tumor size in papillary and follicular thyroid carcinoma. Cancer. 2005;103:11.

20. Vuong HG, Duong UNP, Pham TQ, Tran HM, Oishi N, Mochizuki K, Nakazawa T, Hassell L, Katoh R, Kondo T. Clinicopathological risk factors for distant 
metastasis in differentiated thyroid carcinoma: a meta-analysis. World J Surg. 2018;42:4.

21. Wang F, Yu X, Shen X, Zhu G, Huang Y, Liu R, Viola D, Elisei R, Puxeddu E, Fugazzola L, Colombo C, Jarzab B, Czarniecka A, Lam AK, Mian C, Vianello F, Yip L, Riesco-Eizaguirre G, Santisteban P, O'Neill CJ, Sywak MS, Clifton-Bligh R, Bendlova B, Sykorova V, Wang Y, Liu S, Zhao J, Zhao S, Xing M. The prognostic value of tumor Multifocality in clinical outcomes of papillary thyroid Cancer. J Clin Endocrinol Metab. 2017;102:3241-50.

22. Chow S, Shao J, Wang H. Sample Size Calculations in Clinical Research. 2nd Ed. Chapman \& Hall/CRC Biostatistics Series; 2008. p. 177.

\section{Publisher's Note}

Springer Nature remains neutral with regard to jurisdictional claims in published maps and institutional affiliations.

Ready to submit your research? Choose BMC and benefit from:

- fast, convenient online submission

- thorough peer review by experienced researchers in your field

- rapid publication on acceptance

- support for research data, including large and complex data types

- gold Open Access which fosters wider collaboration and increased citations

- maximum visibility for your research: over $100 \mathrm{M}$ website views per year

At BMC, research is always in progress.

Learn more biomedcentral.com/submissions 